\title{
Problemas de conciencia y de la conciencia
}

Intuimos que una explicación parcial de la problemática que vivimos en el país tiene alguna relación con los problemas relativos a la conciencia. Ciertamente lo relativo a la conciencia no está muy claro; sin embargo, con el objetivo de aclarar esta problemática, el autor pone a consideración el presente comentario.

El pequeño Larousse dice acerca de la "conciencia": "conocimiento, noción, v.g. tener conciencia de sus derechos. Sentimiento interior por el cual aprecia el hombre sus acciones, v.g. nuestra conciencia es nuestro juez. Moralidad, integridad: hombre sin conciencia... Ancho de conciencia, que excusa fácilmente el mal en sí y en los demás".

Esto de la conciencia es un problema bien fregado, no sólo porque tiene un cúmulo de usos y significados, lo cual ya basta para confundir al más pintado, sino porque presenta un sinnúmero de problemas que exigen de nuestra atención y concienzuda reflexión. Y es que cuando de la conciencia se trata, puede ocurrir que el problema que nos ocupa sea de mala o falsa conciencia, de falta de conciencia o bien, que no se tenga nada de conciencia, o peor aún, que teniendo conciencia de lo que hacemos, parezcamos seres sin conciencia.

La conciencia puede ser política, religiosa, ética, humanística, jurídica, ideológica, etc. Pero, en todo caso, se presenta como un atributo muy importante de los seres humanos, al punto de elevarlos o rebajarlos a niveles animalescos cuando se carece de la misma.

Dada la directa vinculación de la conciencia con la realidad, cualquier reflexión que se haga de la misma tiene que ser en relación con la realidad, de tal manera que nos ocuparemos de ella por medio de la reflexión de una serie de casos prácticos acaecidos en nuestro medio y entre algunas personalidades públicas, entre las cuales es común observar serios problemas de conciencia.

Una máxima autoridad de la Policía Nacional Civil, luego de que recapturaran a un peligroso delincuente manifestaba: "Lo mantendré esposado y no me importa lo que digan". El irrespeto a un detenido, independientemente de quien se trate, violentando sus derechos, revela en el funcionario su poca conciencia en materia de derechos humanos. Por otra parte, su prepotencia y altanería evidencian su falta de conciencia cívica e, inclusive, una falsa conciencia en cuanto a sus derechos y deberes. Cuando una autoridad no respeta los derechos de otra persona, de otro ser humano, él también está delinquiendo y se está convirtiendo también en un delincuente. $Y$ resulta fácil para cualquier ciudadano pensar mal y exclamar: "Los cuilios siguen siendo siempre los mismos cuilios". Con lo cual querría reflejar el problema de la impunidad tan corriente en nuestro medio en el pasado. Cuando en la misma autoridad se observan problemas de conciencia, sin lugar a dudas es porque esa sociedad anda muy mal...

Los ecologistas de las UNES, del CESTA, los diputados "disque" de mayor conciencia ecologista y muchos otros más que, con sus imágenes llenaron las pantallas de los televisores, revelan un nivel muy bajo de conciencia ecológica ¿Por qué sostenemos lo anterior, cuando la realidad parece indicar todo lo contrario? Porque pararse frente a los tractores cuando ya habían derribado los árboles indica que lo importante era denunciar el hecho, más que evitar su consumación. Porque pa- 
rarse sólo un rato mientras se les filmaba o fotografiaba sugiere que lo importante era hacer noticia y no evitar que se talaran los árboles. Si la conciencia ecológica de nuestros verdes criollos fuese tan grande, como presumen y aparentan, seguramente que antes de que arrancase el primer tractor, ya hubieran estado amarrados a los árboles y no hubieran abandonado el bosque cafetero ni por un instante siquiera, mientras la Corte Suprema de Justicia no respondiera al sabio recurso interpuesto ante el máximo tribunal de justicia. Pero si ya están mal los verdes, peor es el nivel de conciencia ecológica del Ministro del Medio Ambiente, quien manifestó, con muy ancha conciencia, que lo que se debería de construir en El Espino son edificios de apartamentos, lo cual viene a reflejar el bajo nivel de conciencia del gobiemo de ARENA al haber designado como Ministro del Ambiente a semejante licenciado de hablar agringado.

Ciertamente, la juventud en nuestro medio presenta serios problemas: algunos se entretienen haciendo guerras de maras, y acompañan sus vidas con el alcohol y las drogas, cuando no incursionan en el ámbito de la delincuencia y asaltan y roban a quien se les cruza por su camino. Ello refleja niveles de conciencia torvos y preocupantes. Otros, los que no han caído en ese mundo sin fondo de la drogadicción y la delincuencia, los que parecerían jóvenes modelos muy del gusto de papi y mami, están cautivados por la televisión, los videos, los discos compactos y cualquiera otra basura electrónica. Su conciencia claramente está alienada. Y el grupito de jóvenes excelentes, el de los buenos estudiantes, los reflexivos, los sensibles, esos están más preocupados por encontrar una carrera en la cual ganar mucho dinero, sin mucho trabajo y sin mucho conocimiento; ellos padecen de una clara conciencia crematística. Por estos hechos no se puede menos que pensar que los jóvenes ya no tienen ideales, que tan sólo buscan dinero, lo cual revela un serio problema en términos de falta de conciencia. No hay ningún relevo generacional en cuanto a ideales. Uno se pregunta, no sin cierto dejo de tristeza: ¿quienes serán los nuevos idealistas, los nuevos marxistas, los nuevos revolucionarios? Esta pérdida de conciencia revolucionaria sí podría conducirnos al fin de la historia. Esto es muy grave, sobre todo para países como el nuestro en donde son miles y miles los que claman a gritos por una vida mejor, es decir, por mejores con- diciones de vida y de trabajo. Entre nosotros esta pérdida de conciencia es algo cruel e inhumano, porque no sólo afecta a la juventud sino que a miles de personas pobres y marginadas que podrían beneficiarse con las luchas juveniles $o$, al menos, con la toma de conciencia experimentada por los jóvenes en el proceso de lucha. La mala conciencia, o la falsa conciencia, que se le está generando a la juventud vía medios de comunicación, es algo terrible y mal sano y contra lo cual todo lo que se haga para contrarrestarlo sería poco. Pero para ello, primero es preciso tomar conciencia, hecho que no parece estar ocurriendo.

Mario Acosta, nuestro Ministro del Interior por el partido ARENA, en el poder por un segundo período, gracias a la inconsciencia política de la mayoría de salvadoreños, ante una resolución de la Corte Suprema de Justicia manifestó lo siguiente: "Mueve a risa pensar que cuando uno combate la ilegalidad, uno termina siendo el ilegal" ¿Mala conciencia o falsa conciencia? ¿Qué insinúa el ministro? ¿Acaso que los magistrados son unos payasos? ¿Y por qué considera Mario Acosta que la

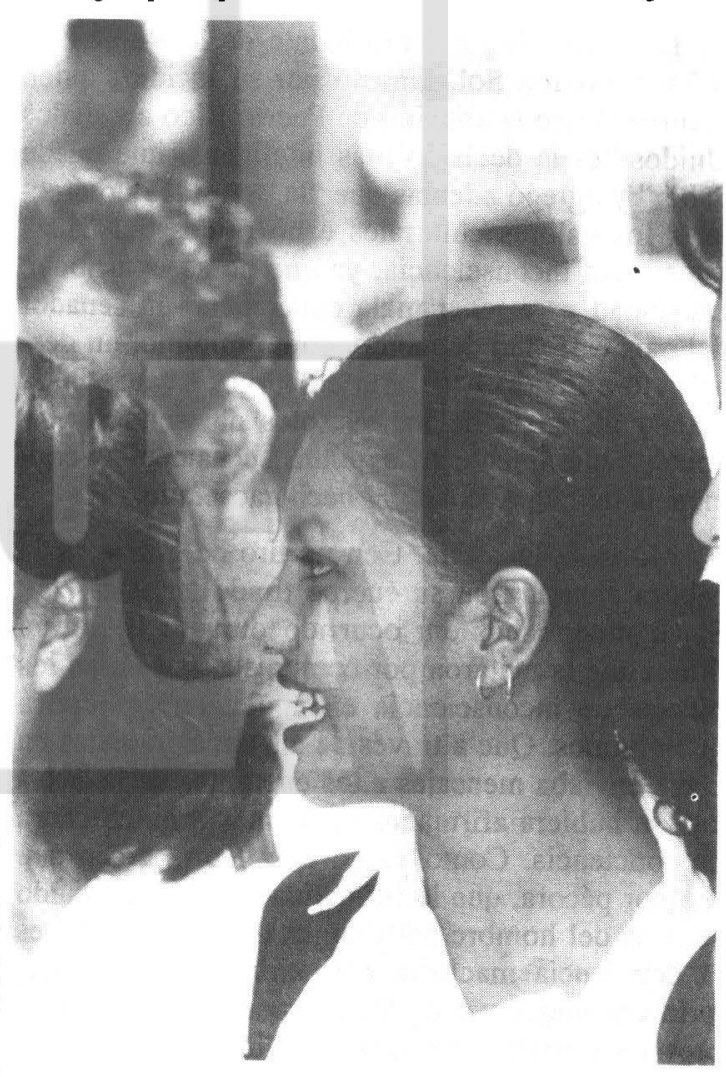


Corte debería ocuparse de conocer el robo que, según él, les hizo el Incafe a ellos, los cafetaleros? Ciertamente parece una falta de conciencia de parte del ministro el faltarle al respeto que se merece el Organo Judicial.

Leiamos en un matutino que la Fuerza Armada Salvadoreña inaugurará la más moderna biblioteca electrónica de Centroamérica, ante lo cual cabe preguntarse: ¿y por qué tales recursos no los maneja el MINED? ¿Por qué los militares tienen que usar los recursos nacionales para realizar actividades que no les corresponden y que, además, es obvio que no están capacitados para hacerlas? Lo anterior revela una clara falta de conciencia en cuanto al uso de los recursos nacionales, que puede tener su origen, o bien ser el fruto de una falsa conciencia, al pensar que como los recursos son nacionales no son de nadie, y que al ser de nadie, cualquiera puede hacer fiesta con ellos. Es muy común que los militares tengan problemas de conciencia, ya sea de mala o falsa conciencia y en períodos difíciles de ancha conciencia 0 , inclusive, de falta de conciencia.

La afirmación del Presidente de la República, señor Calderón Sol, famoso por su lucidez, quien manifestó que la anexión de Puerto Rico a Estados Unidos "es la decisión más inteligente que puede haber" y agregó además que "la estadidad no afectaría los valores culturales e históricos del país". Ante tanta inconsciencia, ya que no se le atribuye capacidad para tener mala conciencia, un senador del país caribeño demandó, como mínimo, un desagravio a Puerto Rico. Sin embargo, a causa de la mala conciencia de los asesores del señor presidente, seguramente ni siquiera se ha tenido conciencia de la gravedad del hecho acaecido.

Murió la locataria. Con un tiro de gracia en la cabeza encontraron su cuerpo tirado en el cafetal. Si su muerte hubiera ocurrido durante la guerra dirian que la mataron por comunista, tales eran los niveles de inconsciencia en aquella negra época que vivimos. Que a través de las ondas radiales en clave enviaba mensajes a los enemigos de la libertad, se hubiera afirmado, sin la más mínima carga de conciencia. Como ya no hay guerra dicen que fue por pécora, que la infidelidad se tolera cuando se trata del hombre pero nunca de la mujer, tal es la conciencia machista predominante, y la locataria era mujer y muy mujer, por eso a los hombres les gustaba. No sabemos quienes la asesinaron. Se necesitaría tener muy mala conciencia pa- ra acusar irresponsablemente a unos inocentes. Pese a todo, ocurre.

Cuando mueren los pobres, el escándalo no es suficiente para mantener el rating de los medios elevado por una semana. Camino a Los Planes, bajo los cafetos, una familia fue encontrada con las cabezas desechas a golpes. La policía dice que no tiene pistas, aunque los vecinos ya les informaron lo que se sabe en el barrio: un agiotista ultrajado decidió cobrarse con vidas humanas la deuda no pagada. Es increíble como una persona pueda vivir con la conciencia tranquila luego de haber cometido tales crímenes abominables. ¿Pero es que se pueden considerar seres humanos a tales bestias carentes de conciencia?

Un joven fue asesinado para simular la muerte de otro que cobraría cuantiosos seguros de vida, conjeturan los periódicos. Se trafica hasta con la propia muerte. Se contrataron sicarios para que asesinaran a un joven, lo quemaran junto con un vehículo - y hasta le arrancaron sus dientes delanteros - para que nadie pudiera definitivamente establecer la identidad verdadera del cadáver carbonizado. Tal pericia y dedicación en un "trabajo" es digna de mejores frutos, procurando vida o bienestar a quienes viven. Pero la inconsciencia en nuestro suelo ha echado raíces y se necesitará mucha conciencia para erradicarla.

A la locataria, como a la familia y al joven plagiado, alguien pagó para asesinarlos y, por tanto, hubo quien recibió la paga por tal necrófilo trabajo. El que la industria de la muerte prospere entre nosotros no debería resultar sorprendente, ya que durante la guerra tanto unos como otros tenían verdugos; sin embargo, es sorprendente que se haya gastado tanto dinero en una supuesta reinserción, además, nadie se acordó de desactivar las mentes asesinas de los sicarios. Por eso, quizá, ahora hay quienes viven de cegar vidas. Su modus vivendi es matar. Matar sin pestañear siquiera, matar a quien les indique el contrato. No importa quien sea, niño, hombre, mujer, joven, anciana o niña. Muy mal anda la conciencia entre nosotros. Por eso se dice, que ya no se tiene conciencia.

Pero la mayor falta de conciencia se observa entre quienes piensan que sus acciones, sus decires, sus opiniones sobre cuestiones, tales como la globalización, el orden económico mundial, etc. tendrán algún sentido o alguna trascendencia. En general, nuestras vidas se están convirtiendo en 
una inmensa obra de teatro: a veces comedia a veces tragedia, pero actuación al fin. Basta con leer los periódicos para encontrar esa cantidad de ac- tos, de escenarios, de artistas sin conciencia, con mala conciencia o falsa conciencia.

Aquiles Montoya 